\title{
Stability difference of each chromosome in Chinese Hamster Ovary cell line
}

\author{
Noriko Yamano ${ }^{1}$, Toshitaka Kumamoto², Mai Takahashi², Jana Frank' ${ }^{1}$, Masayoshi Onitsuka ${ }^{1}$, Takeshi Omasa ${ }^{1,3^{*}}$ \\ From 24th European Society for Animal Cell Technology (ESACT) Meeting: C2P2: Cells, Culture, Patients, Products \\ Barcelona, Spain. 31 May - 3 June 2015
}

\begin{abstract}
Background
The use of biopharmaceutical products that comprise therapeutic antibodies are increasing in the pharmaceutical industry. Chinese hamster ovary $(\mathrm{CHO})$ cell lines are widely used in the field of pharmaceutical industry to produce therapeutic antibodies. CHO DG44 cell line is a dihydrofolate reductase (DHFR)-deficient line, which is frequently used as a host cell while applying the gene amplification method. Since the chromosomes of $\mathrm{CHO}$ cells are unstable, variation in chromosome number occurs in these cells. This study focused on the dynamics of each chromosome during changes in the number of chromosomes. Clones from the $\mathrm{CHO}$ genomic bacterial artificial chromosome (BAC) library, a powerful tool that is expected to cover the entire $\mathrm{CHO}$ DG44 genome [1], were used to distinguish the location of individual chromosomes. In addition to the BAC clones previously known to correspond to the chromosomal locations of CHO DG44 and CHO K1 cell lines [2], sequences of $304 \mathrm{BAC}$ clones that can identify the chromosomal locations in CHO DG44 cell line have been determined in this study. Therefore, our study leads to an understanding of the DNA sequence of individual chromosomes in the genome and the stability of each chromosome to establish high-producing $\mathrm{CHO}$ cell line.
\end{abstract}

\section{Materials and Methods}

CHO DG44 (CHO-DR1000L-4N) cell line was cultured as described previously [3]. Six cell lines were isolated fromCHO DG44: three with 20 (normal) and three with over 30chromosomes. BAC-fluorescence in situ hybridization (FISH) technique was carried out as described previously [1-4] to identify each chromosome and analyze

\footnotetext{
* Correspondence: omasa@bio.eng.osaka-u.ac.jp

'Institute of Technology and Science, Tokushima University, Tokushima, 7708506, Japan

Full list of author information is available at the end of the article
}

the rearrangement of chromosomes in these cell lines. HiSeq sequencing system was used by Takara Bio Inc. (Shiga, Japan)to analyze the BAC clone insert DNA sequences. Host cell (Escherichia coli str. K12 substr. DH10B)-derived sequences and the vector (pBAC-Lac)derived sequences were omitted from the results. Edena v3 software was used to assemble the sequencing results.

\section{Results and Discussion}

While most CHO DG44 cells showed a chromosome number of around 20 (named $\mathrm{A}$ to $\mathrm{T}$ in order of decreasing length [1]), $4 \%$ of the cells had more than 30 chromosomes. A comparison between the two groups revealed that the copy number of specific chromosomes increased or decreased with an overall change in the chromosome number (Table 1). In particular, the copy number of chromosome D was found to regularly decrease despite an increase in the total chromosomes in a cell. On the other hand, chromosomes A or B, E, F, G, H, I, K, M, O, Q, and S doubled in cell lines with a high chromosome number. Chromosomes of the $\mathrm{CHO}$ cell lines are known to rearrange significantly from the original Chinese hamster cells, with the exception of chromosomes A and B [2]. Chromosomes A and B are the only homologous chromosome pair found in $\mathrm{CHO}$ cells [2]. These are considered to be chromosome 1 and stable in $\mathrm{CHO}$ cells.

Chromosomes are listed in order of decreasing length (from A to T). Orange, blue, and pink cells in the chromosome ID column represent an increase, decrease, and no change in number of the corresponding chromosome respectively.

Further analyses were performed to determine the sequences of the 304 BAC clone inserts. The size distribution of BAC DNA inserts estimated by sequence assembling results is presented in the figure (Figure 1). By determining the sequence of BAC clone DNA, 
Table 1. Copy number of individual chromosomes in $\mathrm{CHO}$ cells with chromosome number variation

\begin{tabular}{lll}
\hline Chromosome ID & \multicolumn{2}{l}{ Chromosome number in a cell } \\
\hline A, B & 20 & over 30 \\
C & $2(100 \%)$ & $3(100 \%)$ \\
D & $1(100 \%)$ & $1(80100 \%), 2(20 \%)$ \\
E & $0,(55 \%), 1(45 \%)$ & $0(100 \%)$ \\
F & $1(100 \%)$ & $2(100 \%)$ \\
G & $1(100 \%)$ & $2(100 \%)$ \\
H & $1(100 \%)$ & $2(100 \%)$ \\
I & $1(100 \%)$ & $2(100 \%)$ \\
J & $1(100 \%)$ & $1(10 \%), 2(80 \%), 3(10 \%)$ \\
K & $2(100 \%)$ & $2(100 \%)$ \\
L & $1(100 \%)$ & $1(40 \%), 2(60 \%)$ \\
M & $1(83 \%), 2(17 \%)$ & $1(71 \%), 2(29 \%)$ \\
N & $1(100 \%)$ & $2(100 \%)$ \\
O & $0(100 \%)$ & $0(80 \%), 1(20 \%)$ \\
P & $1(100 \%)$ & $9(95 \%)$ \\
Q & $1(60 \%)$ & $1(40 \%)$ \\
R & $1(100 \%)$ & $2(100 \%)$ \\
S & $2(100 \%)$ & $2(100 \%)$ \\
T & $1(100 \%)$ & $1(17 \%), 2(83 \%)$ \\
\hline
\end{tabular}

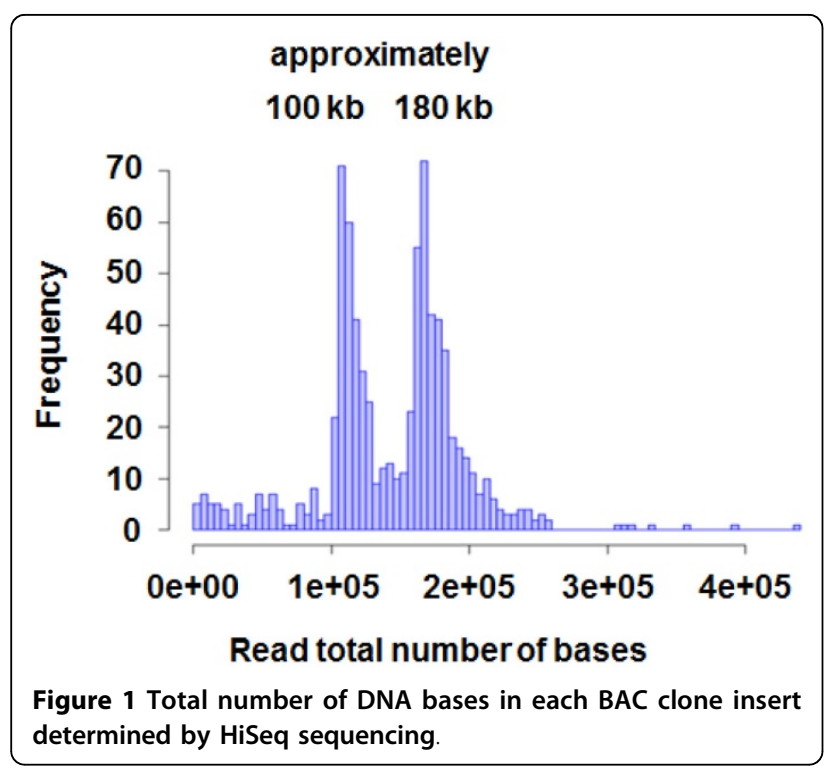

genome sequence of each chromosome in CHO DG44 and $\mathrm{CHO} \mathrm{K} 1$ cell lines was revealed. As a next step, it is important to construct a screening system for isolating specific BAC clones containing particular sequences to find gene locations in the individual chromosomes.

\section{Conclusions}

Our results suggest that chromosome stability differs across individual chromosomes in $\mathrm{CHO}$ cells. In recent years, site-specific integration of expression vectors by gene targeting has become a new approach to construct stable cell lines. Overlapping sequences on stable chromosomes appear to be attractive candidate locations for establishing high-yielding $\mathrm{CHO}$ cell lines.

\section{Acknowledgements}

This work was partly funded by a grant for the Project focused on developing key technology of discovering and manufacturing drug for nextgeneration treatment and diagnosis from the Ministry of Economy, Trade and Industry of Japan and partly by a Grant-in-Aid for Scientific Research from the Japan Society for the Promotion of Science (JSPS) (No.26630433, 26249125)

\section{Authors' details}

'Institute of Technology and Science, Tokushima University, Tokushima, 7708506, Japan. ${ }^{2}$ Graduate School of Advanced Technology and Science, Tokushima University, Tokushima, 770-8506, Japan. ${ }^{3}$ Graduate School of Engineering, Osaka University, Osaka, 565-0871, Japan.

Published: 14 December 2015

\section{References}

1. Takeshi Omasa, Yihua Cao, Joon Young Park, Yasuhiro Takagi, Shuichi Kimura, Hidenori Yano, Kohsuke Honda, Shuichi Asakawa, Nobuyoshi Shimizu, Hisao Ohtake: Bacterial artificial chromosome library for genome-wide analysis of Chinese hamster ovary cells. Biotechnol Bioeng 2009, 104(5):986-994.

2. Yihua Cao, Shuichi Kimura, Takayuki Itoi, Kohsuke Honda, Hisao Ohtake, Takeshi Omasa: Construction of BAC-based physical map and analysis of chromosome rearrangement in Chinese hamster ovary cell lines. Biotechnol Bioeng 2012, 109(6):1357-1367.

3. Tomohiro Yoshikawa, Fumi Nakanishi, Yuki Ogura, Daisuke Oi, Takeshi Omasa, Yoshio Katakura, Michimasa Kishimoto, Ken-ichi Suga: Amplified gene location in chromosomal DNA affected recombinant protein production and stability of amplified genes. Biotechnol Prog 2000, 16(5):710-715.

4. Tomohiro Yoshikawa, Fumi Nakanishi, Seima Itami, Daisuke Kameoka, Takeshi Omasa, Yoshio Katakura, Michimasa Kishimoto, Ken-ichi Suga: Evaluation of stable and highly productive gene amplified $\mathrm{CHO}$ cell line based on the location of amplified genes. Cytotechnology 2000, 33(13):37-46.

doi:10.1186/1753-6561-9-S9-P1

Cite this article as: Yamano et al.: Stability difference of each

chromosome in Chinese Hamster Ovary cell line. BMC Proceedings 2015 9(Suppl 9):P1.

Submit your next manuscript to BioMed Central and take full advantage of:

- Convenient online submission

- Thorough peer review

- No space constraints or color figure charges

- Immediate publication on acceptance

- Inclusion in PubMed, CAS, Scopus and Google Scholar

- Research which is freely available for redistribution 